\title{
Systematic Advance Care Planning and Potentially Avoidable Hospitalizations of Nursing
}

\section{Facility Residents}

Authors: Susan E. Hickman, $\mathrm{PhD}^{1,2}$, Kathleen T. Unroe, MD, $\mathrm{MHA}^{2,3,4}$, Mary Ersek, PhD, RN, FPCN ${ }^{5,6}$ Timothy E. Stump, MA ${ }^{3}$, Wanzhu Tu, $\mathrm{PhD}^{3,4}$, Monica Ott, MD', ${ }^{3,4}$, Greg A. Sachs, MD ${ }^{2,3,4}$

${ }^{1}$ School of Nursing, Indiana University, Indianapolis, Indiana

${ }^{2}$ RESPECT (Research in Palliative and End-of-Life Communication and Training) Signature

Center, Indiana University Purdue University Indianapolis, Indianapolis, Indiana

${ }^{3}$ School of Medicine, Indiana University, Indianapolis, Indiana

${ }^{4}$ Regenstrief Institute, Indianapolis, Indiana

${ }^{5}$ Department of Veterans Affairs, Philadelphia. PA

${ }^{6}$ School of Nursing, University of Pennsylvania, Philadelphia, Pennsylvania

Corresponding Author:

Susan E. Hickman, PhD

Indiana University School of Nursing

600 Barnhill Drive, e419

Indianapolis, IN 46202

hickman@iu.edu

Short running title: Advance care planning in nursing facilities

Funding Source: This work was supported by the U.S. Department of Health and Human

Services, Centers for Medicare and Medicaid Services [Funding Opportunity 1E1CMS331488].

The opinions expressed in this article are the authors' own and do not reflect the view of the U.S.

Department of Health and Human Services, Centers for Medicare and Medicaid Services.

Keywords: Nursing home; nursing facility; advance care planning; palliative care

Abstract Word Count: 296

Manuscript Word Count: 3062

This is the author's manuscript of the article published in final edited form as:

Hickman, S. E., Unroe, K. T., Ersek, M., Stump, T. E., Tu, W., Ott, M., \& Sachs, G. A. (2019). Systematic Advance Care Planning and Potentially Avoidable Hospitalizations of Nursing Facility Residents. Journal of the American Geriatrics Society, 67(8), 1649-1655. https://doi.org/10.1111/jgs.15927 


\section{Abstract}

Background/Objectives: The Optimizing Patient Transfers, Impacting Medical quality, Improving Symptoms - Transforming Institutional Care (OPTIMISTIC) project is a successful, multicomponent demonstration project to reduce potentially avoidable hospitalizations of long-stay nursing facility residents. Systematic advance care planning (ACP) is a core component of the intervention, based on research suggesting ACP is associated with decreased hospitalizations of nursing facility residents. The purpose of this study was to describe associations between ACP documentation resulting from the OPTIMISTIC intervention and hospitalizations.

Design: Specially trained project nurses were embedded in 19 nursing facilities and systematically engaged in ACP as part of larger demonstration project.

Participants: Residents $(n=1482)$ enrolled in the demonstration project for a minimum of 30 days between January 1, 2015 and June 30, 2016.

Measurements: ACP status: 1) Physician Orders for Scope of Treatment (POST) comfort measures or do not hospitalize orders; 2) ACP orders with no hospitalization limit (e.g., code status only); and 3) no ACP; potentially avoidable and all-cause hospitalizations per 1000 resident days.

Results: Residents with POST comfort measures/do-not-hospitalize orders $(33.2 \%$ or $n=493)$ were less likely than residents with no ACP $(14.7 \%$ or $n=218)$ to experience a potentially avoidable hospitalization $(p=.001)$ or all-cause hospitalization $(p=.001)$. These differences became statistically non-significant after adjusting for age, functional status, and cognitive functioning.

Conclusion: In this successful multi-component demonstration project to reduce potentially avoidable hospitalizations, ACP outcomes were not associated with hospitalization rates of nursing facility residents after adjusting for resident characteristics. These findings highlight the challenge of measuring the contributions of individual components of complex, multicomponent interventions. Associations between lower hospitalization rates and ACP completion may be 
influenced by contextual factors such as clinical expertise and resources to manage acute conditions leading to hospitalization, in addition to interventions to increase ACP. 
Advance care planning (ACP) is integral to providing person-centered care in nursing facilities. ${ }^{1,2}$ ACP is the process of discussing and documenting goals, values, and treatment preferences. ${ }^{3} \mathrm{ACP}$ helps support informed, values-based decision-making that is essential to decision quality and improving end-of-life care. ${ }^{4}$ In the absence of recorded preferences for treatment, staff and providers act on system defaults and provide all available interventions. ${ }^{5}$

A primary goal of ACP is to ensure that care provided is concordant with patient goals. ${ }^{6}$ In nursing facilities, residents and family members of incapacitated residents frequently elect to focus on comfort and avoid hospital transfers. ${ }^{7-9}$ Hospitalizations are associated with negative consequences for nursing facility residents. ${ }^{10}$ Several studies have found associations between comfort-focused goals of care and lower rates of hospitalization. ${ }^{11-14}$ These associations suggest that preferences and goals of care may be important factors in hospital transfer decisions. . $^{75,16}$ Furthermore, earlier ACP is identified by nursing facility staff an important strategy to reduce potentially avoidable hospitalizations. ${ }^{17}$

Palliative care and ACP is one of 3 core components of the CMS-funded clinical demonstration project called OPTIMISTIC (Optimizing Patient Transfers, Impacting Medical quality, Improving Symptoms - Transforming Institutional Care) designed to reduce potentially avoidable hospitalizations of long-stay nursing facility residents. ${ }^{18}$ Other components include improving medical care consistent with the principles of geriatric medicine and enhancing transitions between the nursing facility and hospital. ${ }^{19}$ Embedded OPTIMISTIC RNs and supporting NPs facilitated ACP conversations with residents in participating facilities. ${ }^{20} \mathrm{An}$ external evaluation of the OPTIMSTIC project using claims data found a $40 \%$ reduction in potentially avoidable hospitalizations and a $25 \%$ reduction in all-cause hospitalizations in comparison to a matched control group. ${ }^{21}$ In qualitative interviews, stakeholders identified ACP and use of the Physician Orders for Scope of Treatment (POST) as a key reason for this reduction. ${ }^{21,22}$ 
The OPTIMISTIC project provides an opportunity to evaluate the effects of systematic ACP and recorded treatment preferences on hospitalizations rates. The purpose of this study was to assess the contributions of ACP to the observed reductions in potentially avoidable hospitalizations in the context of a multicomponent intervention. We hypothesized that residents with ACP discussions resulting in documentation of Comfort Measures/Do Not Hospitalize orders would be less likely to be hospitalized than residents with ACP discussions resulting in no limits on hospitalization or residents with no ACP at all.

\section{Methods}

\section{Setting}

The study was conducted at 19 urban and suburban Indiana nursing facilities participating in the OPTIMISTIC project. The analysis includes residents enrolled in OPTIMISTIC between January 1, 2015 and June 30, 2016. The Indiana University Institutional Review Board determined that the study was exempt.

\section{$\underline{\text { Participants }}$}

Per CMS requirements, eligible residents were required to have a minimum length of stay of 100 days in the facility and not be enrolled in Medicare managed care.${ }^{21}$ Residents were enrolled passively with less than $1 \%$ electing to opt out. For the analysis, we used the resident's last nursing facility stay and included residents who had been enrolled in OPTIMISTIC for at least 30 days to provide a minimum amount of time for outcomes to occur $(n=2391)$. We eliminated 170 residents who did not have matching records between the project clinical database and the MDS, 735 residents with ACP documentation that did not involve OPTIMISTIC staff, and 4 residents with ACP coding errors, resulting in a sample of 1482 residents.

\section{Procedures}


OPTIMISTIC RNs were certified in the End of Life Nursing Education Curriculum (ELNEC) Geriatric ${ }^{23}$ and the Respecting Choices Advanced Steps POLST facilitation model. ${ }^{24}$ OPTIMISTIC RNs provided education and training to support ACP within the facilities.

A systematic, structured ACP assignment process was developed. ${ }^{20}$ OPTIMISTIC RNs were provided with a list of 5-10 resident names each month with the expectation that each would be offered the opportunity to engage in an ACP discussion. Additionally, OPTIMISTIC RNs were encouraged to facilitate ACP discussions with residents who experienced a change of condition and to be responsive to referrals by facility staff. OPTIMISTIC RNs recorded the outcome of the ACP encounter including documentation of preferences on ACP tools (e.g., POST) in the project database.

\section{Data Collection Tools}

Resident Characteristics. Resident characteristics were obtained from the Minimum Data Set (MDS) 3.0. Cognitive functioning and activities of daily living (ADL) scores reflecting functional status were calculated from MDS data using standard assessments. ${ }^{25,26}$ The MDS assessment closest to the ACP discussion was used for analysis.

ACP Status. ACP focused on the communication of preferences as medical orders as these were most relevant to decisions about hospitalization. Tools used included: code status orders (do not resuscitate (DNR); attempt resuscitation/Full Code); Do Not Hospitalize (DNH) orders; and the Indiana Physician Orders for Scope of Treatment (POST) form. ${ }^{27}$ The Indiana POST permits documentation of orders about code status, medical interventions, antibiotics, and artificial nutrition. Medical intervention order options included: Comfort Measures (focus on symptom management, avoid hospitalization); Limited Interventions (no intubation but hospitalization permitted and preference to avoid the intensive care unit); and Full Intervention (provide all available treatments including hospitalization and the intensive care unit). In Indiana, residents must have a qualifying diagnosis (e.g., advanced chronic progressive illness or frailty, a terminal condition, or be unlikely to survive CPR) and retain decisional capacity in order to 
complete a POST. Only a legally appointed representative may completed a POST form for a resident who lacks decisional capacity. ${ }^{2}$ Resulting ACP documentation was entered into the medical record and recorded in the OPTIMISTIC clinical data base. ${ }^{20}$

Hospitalizations. Hospitalizations were tracked using the RedCAP ${ }^{28}$ database. A root cause analysis was performed by OPTIMISTIC RNs on all hospital transfers that included an assessment of avoidability based on the nurse's clinical judgment following a review of available information. Hospitalizations were classified as avoidable/potentially avoidable or unavoidable/potentially unavoidable based on OPTIMISTIC RN ratings. ${ }^{29}$ The total number of all-cause and potentially avoidable hospitalizations were summed during the length of observation for each resident. Each length of observation began with the maximum of January 1, 2015 and ACP date (i.e., whichever occurred later) and ended with the minimum of discharge date and June 30, 2016 (i.e., whichever occurred earlier).

Analysis

ACP status groups were created for analytical purposes. Comfort Measures/Do Not Hospitalize included all residents who had orders documenting preferences for comfort measures or $\mathrm{DNH}$. We combined these two groups as these orders specifically indicate a preference to avoid hospitalization unless necessary to ensure comfort. ACP with no Hospitalization Limits included residents with orders for POST limited additional interventions, POST full intervention, DNR, and full code. No ACP consisted of residents with no POST or code status order in the medical record and no ACP discussion with the OPTIMSITC RN.

Generalized mixed effect linear regression models for count data with a negative binomial distribution were used to compare the rates of all-cause hospitalization and potentially avoidable hospitalization among the three resident groups. We use the number (or count) of allcause and potentially avoidable hospitalizations as outcomes for these models. To account for varying lengths of observation across residents, we included in the model the natural logarithmtransformed length of observation as an off-set parameter. To account for within-facility 
clustering, we treated residents within each of the 19 facilities as correlated observations in the adjusted models. To determine the relationship between ACP groups and hospitalizations, bivariate and multivariable models were assessed. Pairwise comparisons were made between the three ACP groups. Group effects were characterized with incidence rate ratios (IRRs), associated $95 \%$ confidence intervals and p-values. Tukey-adjusted confidence intervals for all pairwise comparison and p-values were calculated to account for multiple comparisons. Tukeyadjusted $p$ values less than 0.05 were considered statistically significant. Covariates for the multivariable models included gender, race, age, hospice, end stage renal disease, cognitive function score, depression, and ADL score. Model estimation was performed using the PROC GENMOD procedure in SAS version $9.4 .^{30}$

\section{Results}

\section{Participant Characteristics and ACP Status}

Participating residents $(n=1482)$ had an average length of stay of 1001 days $(S D=794$; range $=130-6749)$. The average length of observation was 272.4 days $(S D=189)$, with a median of 234 days (range $=1-547$ days). Residents were predominantly female $(67.5 \%)$ and white $(72.5 \%)$ with an average age of 79.2 years (standard deviation $=12.7)$. About a third $(31.4 \%$ or $n=455)$ were cognitively intact. Residents with ACP documentation were older, more likely to be cognitively impaired, and had lower functional status than resident with no ACP documentation (see Table 1).

ACP status included medical orders denoting 1) comfort measures or $\mathrm{DNH}(33 \%$ or $n=$ 493), 2) no hospitalization limits (code status only or POST with limited or full intervention orders: $52 \%$ or $n=771)$, or 3 ) no ACP $(14.7 \%$ or $n=218)$. Almost all comfort measures/DNH residents $(n=480,97.4 \%)$ had the orders addressing hospitalization limitations recorded on a POST form. Among residents with no hospitalization limits, half $(n=355,46 \%)$ had a POST form (see Table 2). 


\section{$\underline{\text { ACP Status and Hospitalizations }}$}

Unadjusted rates of hospitalizations and potentially avoidable hospitalizations differed between groups (see Table 3). Incidence rate ratios (IRR) from bivariate and multivariable models of all-cause and potentially avoidable hospitalizations are shown in Figure 1 for the three ACP status groups. Bivariate models including only the variable for ACP status indicated that compared to the comfort measures/DNH group, the overall all-cause hospitalization incident rate was higher for residents having $A C P$ with no hospitalization limits $(I R R=1.48, p=.009)$ and for those with no ACP (IRR = 1.93, $p=.001)$. Also, compared to the comfort measures/DNH group, the incident rate for avoidable hospitalizations was higher for those with no ACP (IRR = 2.52, $p=.001)$. Comparisons between those with no ACP versus ACP with no hospitalization limits were not statistically significant for either overall all-cause $(p=.412)$ or avoidable hospitalizations $(p=.105)$. Multivariable models were adjusted for age, gender, race, hospice/end stage renal disease, cognitive functioning, and functional status. No statistically significant differences were found for any pairwise comparison between ACP groups in multivariable models $(p>.094)$.

Several covariates were significant in the multivariable models including age, cognitive functioning, and functional status. For residents aged 65 years and older compared to those younger than 65 years, the incident rate was lower for all-cause hospitalizations (IRR=0.59, $p$ $<.001)$ and potentially avoidable hospitalizations ( $I R R=0.45, p=.001)$. Also, compared to residents who were cognitively intact, the incident rate of all-cause hospitalization was lower for residents with moderate $(I R R=0.64, p=.011)$ and severe $(I R R=0.60, p=.005)$ cognitive impairment. Similarly, the incident rate of avoidable hospitalization was lower for residents with moderate impairment vs. those cognitively intact $(I R R=0.53, p=.017)$. In contrast, the hospital incident rate was higher for each additional level of assistance (or dependence) on the ADL functional status score both for all-cause hospitalizations $(\operatorname{IR} R=1.03, p=.008)$ and potentially avoidable hospitalizations (IRR=1.04, $\mathrm{p}=.010)$. 


\section{Discussion}

ACP interventions have been associated with an increase in goal-concordant care and lower rates of hospitalizations in populations who elect comfort measures. We describe the relationship between recorded treatment preferences and hospitalization rates of long stay nursing facility residents enrolled in a large, non-randomized demonstration project designed to reduce hospital transfers. We observed significantly lower hospitalization rates in residents who had documentation of ACP discussions with trained facilitators resulting in orders for comfort measures/DNH in comparison with those who had ACP with no hospitalization limits or no ACP. However, the association became statistically nonsignificant after adjusting for facility-clustering and resident variables. This suggests that the differences in hospitalization rates in this sample may be better explained, at least in part, by resident characteristics such as age, functional status, and cognitive functioning than by ACP status alone. ${ }^{31}$ This reflects prior research suggesting preferences for comfort focused care increase with advanced age and decreased cognition..$^{9,32-34}$

The lack of significant association between ACP and hospitalization rates is particularly interesting in light of two qualitative evaluations identifying OPTIMISTIC's focus on ACP as a key contributor to decreased hospitalizations. ${ }^{21,22}$ Facility leadership reported "that having completed POST forms has contributed to decreasing potentially avoidable hospitalizations" because there were less likely to panic and call 911 in crisis when preferences were known. It may be that changes in hospitalization rates were attributed to ACP outcomes because POST was a new easily identified practice change in a setting where there was an overall shift in facility culture focused on treating residents in house. ${ }^{21}$

Study findings differ from earlier randomized controlled trials in nursing facilities identifying associations between the documentation of a comfort-focused plan of care and reduced use of interventions including hospitalizations. ${ }^{7,35,36}$ The lack of significance in this study may be partly explained by the study design, which was observational. Age, functional 
status, and cognition were associated with potentially avoidable hospitalizations. Specifically, residents who were older and more cognitively impaired were less likely to be transferred. These findings are similar to prior research ${ }^{31}$ and may reflect preferences for a focus on comfort in resident with dementia. ${ }^{9}$ The fact that residents who were less functional transferred more often than residents with relatively better functioning irrespective of ACP suggests that severity of illness may (appropriately) have greater weight than preferences during transfer decisions. It is worth nothing that even when there are preferences to avoid hospitalization, it is still necessary for residents who cannot be safely managed or kept comfortable in the facility. In prior research, $13 \%$ of residents with comfort care orders were transferred to the hospital during a 60 day observation period, ${ }^{14}$ and these transfers were consistent with the goals of comfort $74 \%$ of the time..$^{8}$ In Phase II of OPTIMISTIC, CMS is testing new billing codes to provide nursing facilities with additional reimbursement when caring for residents with specific medical diagnoses, ${ }^{19,37}$ which may increase capacity and further reduce potentially avoidable hospitalizations. Although controlling for resident characteristics eliminated differences between ACP groups in hospitalization rates, there may be other, unmeasured differences between residents confounding this analysis, such as eligibility for POST forms.

An external evaluation found that the Indiana OPTIMISTIC project substantially reduced hospitalizations. ${ }^{21}$ However, identifying which intervention components were most effective is challenging. This demonstration project included a multi-modal intervention, with other components focused on improving medical care and transitions between settings, making it difficult to separate out the effects of each individual intervention component. Novel methodologies, such as qualitative comparative analysis, may be useful in isolating the contributions of intervention components as well as internal and external factors such as staff turnover ${ }^{38}$ The components effect on hospitalization rates may also be additive, making it problematic to identify the contributions of a specific intervention. The effect of the whole intervention may be greater than the sum of its parts. It is also possible that the effect of ACP 
was muted by the use of multiple strategies to reduce potentially avoidable hospitalizations. Moreover, overall hospitalization rates in these settings were relatively low. In settings where there are fewer efforts or where hospitalization rates are higher, ACP may have a greater effect on hospitalization decisions (particularly those that are potentially avoidable) than in settings where there is a concerted effort to reduce potentially avoidable hospitalizations through a variety of strategies. In other words, when there is attention focused on increasing the capacity to care for residents in the facility, resident preferences may be less important in transfer decisions than in settings where transfer to the hospital is the default first choice. $\underline{\text { Limitations }}$

This study was conducted as part of a larger demonstration project that provided additional resources and support to facilities. The ACP discussions were facilitated by welltrained facilitators embedded in facilities and therefore may not be generalizable to ACP discussions conducted in usual clinical care settings. An inherent limitation of the current report is the observational nature of the study where the selection of comfort measures and willingness to engage in ACP reflected the residents' preference, rather than designation from a random assignment. The non-randomized design prevents us from presenting the findings with causal interpretations. Although controlling for resident characteristics eliminated the differences in hospitalization rates between ACP groups, there may be other, unmeasured differences between residents confounding this analysis, such as eligibility for POST forms among the $54 \%$ of residents with code status only orders. It is possible many of these residents had clearly defined preferences about hospitalization that were not reflected in the documentation, yet still influenced transfer decisions.

The lack of significant associations between ACP resulting from facilitated conversations and hospitalization rates does not negate the importance of ACP for nursing facility residents. The goal of ACP discussions and documentation is to give voice to resident/surrogates' values and goals of care. Care consistency with documented preferences is recognized as a key 
palliative care quality indicator ${ }^{39}$ and the most highly rated outcome of successful ACP. ${ }^{6,40}$ Other important ACP outcomes include the identification and documentation of a surrogate decisionmaker, and increased frequency and enhanced quality of discussions with surrogates and residents. ${ }^{6}$ Moreover, ACP is associated with increased patient and family satisfaction with care, decreased decisional regret and conflict, and fewer symptoms of post-traumatic stress among family members ${ }^{41}$ Assessment of these important outcomes was outside the scope of this project.

Additionally, the link between ACP and hospitalization is likely dependent on several factors, such as the facility's capacity to proactively identify and respond to a resident's change in condition or family confidence in the facility. ACP may result in lower hospitalization rates if residents prefer to avoid hospitalization, the hospitalization is potentially avoidable based on the clinical presentation and resident preferences, ${ }^{8}$ and adequate care can be provided in the facility. The clinician must also be made aware of these goals by staff when contacted about a change of condition and be comfortable honoring preferences. ACP implementation should focus on both systematically offering ACP to residents and ensuring systems are in place to support best practice and that all members of the care team understand their role in the process.

\section{Conclusion}

An external evaluation found that the OPTIMISTIC multi-component demonstration substantially reduced hospitalizations. ${ }^{21}$ Stakeholders identified ACP as the primary explanation for the project's success, an attribution consistent with prior research on ACP and hospitalization rates. Although ACP status was significantly associated with lower rates of potentially avoidable and all cause hospitalization in this analysis, these associations became nonsignificant after adjusting for resident characteristics including age, cognitive functioning, and functional status. These findings highlight the challenge of measuring the contributions of individual components of complex, multicomponent interventions. Findings also suggest that 
associations between lower hospitalization rates and ACP completion may be influenced by contextual factors such as clinical expertise and resources to manage acute conditions as well as interventions to increase ACP.

\section{$\underline{\text { Acknowledgements }}$}

The authors would like to acknowledge John Price, MS, for his support in data preparation, Erin O'Kelly Phillips, MPH, for her assistance with manuscript preparation, the OPTIMISTIC RNs and NPs, participating nursing facilities, and the residents enrolled in OPTIMISTIC.

Financial Disclosure. The OPTIMISTIC demonstration project is supported by the U.S. Department of Health and Human Services, Centers for Medicare and Medicaid Services (Funding Opportunity 1E1CMS331082-04-00). The content is solely the responsibility of the authors and does not necessarily represent the official views of the CMS Innovation Center and the CMS Medicare-Medicaid Coordination Office.

Conflicts of Interest. Dr. Unroe is CEO and Founder of Care Revolution, Inc, a program to train nurses to reduce nursing home hospital transfers

Author Contributions. All authors contributed to the study design, interpretation of findings, writing and review of the manuscript. Wanzhu Tu and Timothy Stump performed analyses.

Sponsor's Role. The investigators retained independence in the conduct of this research. 


\section{References}

1. Advance care planning for older adults. American Geriatrics Society (online). Available at www.americangeratrics.org. Accessed October 5, 2018.

2. Carr D, Luth AL. Advance care planning: Contemporary issues and future directions. Innov Aging 2017;1:1-10.

3. Rietjens JAC, Sudore RL, Connolly M, et al. Definition and recommendations for advance care planning: an international consensus supported by the European Association for Palliative Care. Lancet Oncol 2017;18:e543-e551.

4. Pizzo P, Walker D, Bomba P. Dying in America: Improving Quality and Honoring Individual Preferences near the End of Life. Washington, DC: Institute of Medicine. 2014.

5. Cohen AB, Knobf MT, Fried TR. Do not hospitalize orders in nursing homes: Call the family instead of calling the ambulance. J Am Geriatr Soc 2017;65:1573-1577.

6. Sudore RL, Heyland DL, Lum HD, et al. The outcomes that define successful advance care planning: A Delphi Panel Consensus. J Pain Symptom Manage 2018;55:245-255.

7. Hanson LC, Zimmerman S, Song M-K, et al. Effect of the Goals of Care Intervention for Advanced Dementia: A Randomized Clinical Trial. JAMA Intern Med 2017;177(1):24-31.

8. Hickman SE, Nelson CA, Moss A, Tolle SW, Perrin N, Hammes BJ. The consistency between treatments provided to nursing facility residents and orders on the Physician Orders for Life-Sustaining Treatment (POLST) Form. J Am Geriatr Soc 2011;59: 20912099.

9. Mitchell SL, Palmer JA, Volandes AE, Hanson LC, Habtermarian D, Shaffer ML. Level of care preferences among nursing home residents with advanced dementia. J Pain Symptom Manage 2017;54:340-345.

10. Ouslander JG, Lamb G, Perloe M, et al. Potentially Avoidable Hospitalizations of Nursing Facility Residents: Frequency, Causes, and Costs. J Am Geriatr Soc 2010;58(4):627635.

11. Grabowski DC, Stewart KA, Broderick SM, Coots LA. Predictors of Nursing Home Hospitalization: A Review of the Literature. Med Care Res Rev 2008;65(1):3-39.

12. Nicholas LH, Langa KM, Iwashyna TJ, Weir DR. Regional Variation in the Association between Advance Directives and End-of-Life Medicare Expenditures. JAMA 2011;306(13):1447-1453.

13. Hammes BJ, Rooney BL, Gundrum JD, Hickman SE, Hager H. The POLST Program: A retrospective review of the demographics of use and outcomes in one community where advance directives are prevalent. J Palliat Med 2012;15:1-9.

14. Hickman SE, Nelson CA, Perrin NA, Moss AH, Hammes BJ, Tolle SW. A Comparison of 
Methods to Communicate Treatment Preferences in Nursing Facilities: Traditional Practices Versus the Physician Orders for Life-Sustaining Treatment Program. J Am Geriatr Soc 2010;58(7):1241-1248.

15. Levy C, Morris M, Kramer A. Improving end-of-life outcomes in nursing homes by targeting residents at high-risk of mortality for palliative care: Program description and evaluation. J Palliat Med 2008;11(2):217-25.

16. Martin RS, Hayes B, Gregorevic K, Lim WK. The Effects of Advance Care Planning Interventions on Nursing Home Residents: A Systematic Review. J Am Med Dir Assoc 2016;17(4):284-93.

17. Ouslander JG, Naharci I, Engstrom G, et al. Root Cause Analyses of Transfers of Skilled Nursing Facility Patients to Acute Hospitals: Lessons Learned for Reducing Unnecessary Hospitalizations. J Am Med Dir Assoc. 2016;17(3):256-262.

18. Unroe KT, Nazir A, Holtz LR, et al. The Optimizing Patient Transfers, Impacting Medical Quality, and Improving Symptoms: Transforming Institutional Care Approach: Preliminary Data from the Implementation of a Centers for Medicare and Medicaid Services Nursing Facility Demonstration Project. J Am Geriatr Soc 2015;63(1):165-169.

19. Optimizing Patient Transfers, Impacting Medical Quality, and Improving Symptoms: Transforming Institutional Care: The OPTIMISTIC Project. 2019; https://www.optimisticcare.org/. Accessed January 10, 2019.

20. Hickman SE, Unroe KT, Ersek M, Buente BB, Sachs GA. An Interim Analysis of an Advance Care Planning Intervention in the Nursing Home Setting. J Am Geriatr Soc 2016:64; 2385-2392.

21. Ingber MJ, Feng Z, Khatutsky G, et al. Initiative To Reduce Avoidable Hospitalizations Among Nursing Facility Residents Shows Promising Results. Health Aff (Millwood) 2017;36:441-50.

22. Ersek M, Hickman SE, Thomas AC, Bernard B, Unroe KT. Stakeholder perspectives on the Optimizing Patient Transfers, Impacting Medical Quality, and Improving Symptoms: Transforming Institutional Care (OPTIMISTIC) Project. Gerontologist 2017:58; 11771187.

23. Kelly K, Ersek M, Virani R et al. End-of-Life Nursing Education Consortium. Geriatric training program: Improving palliative care in community geriatric care settings. J Gerontol Nurs 2008;34:28-35.

24. Respecting Choices Advanced Steps. Respecting Choices (online). Available at www.respectingchoices.org. Accessed December 6, 2018.

25. Morris JN, Fries BE, Morris SA. Scaling ADLs within the MDS. J Gerontol A Biol Sci Med Sci 1999:54(11); M546-M553.

26. Thomas KS, Dosa D, Wysocki A, Mor V. The minimum data set 3.0 cognitive function scale. Med Care 2017:55(9); e68. 
27. The Indiana Physician Orders for Scope of Treatment (POST) Program. Indiana Patient Preferences Coalition (online). Available at www.indianapost.org. Accessed December 6, 2018.

28. Harris PA, Taylor R, Thielke R, Payne J, Gonzalez N, Conde JG. Research electronic data capture (REDCap) - A metadata-driven methodology and workflow process for providing translational research informatics support, J Biomed Inform. 2009 Apr;42(2):377-81.

29. Unroe KT, Carnahan JL, Hickman SE, Sachs GA, Hass Z, Arling G. The Complexity of Determining Whether a Nursing Home Transfer Is Avoidable at Time of Transfer. J Am Geriatr Soc 2018;66(5):895-901.

30. SAS Institute Inc. 2018. SAS/STAT® 14.2 User's Guide. Cary, NC: SAS Institute Inc.

31. Kane RL, Huckfeldt $P$, Tappen $R$, et al. Effects of an Intervention to Reduce Hospitalizations From Nursing Homes: A Randomized Implementation Trial of the INTERACT Programlnterventions to Reduce Hospitalizations From Nursing HomesInterventions to Reduce Hospitalizations From Nursing Homes. JAMA Intern Med. 2017;177(9):1257-1264.

32. Hickman SE, Keevern E, Hammes BJ. Use of the Physician Orders for Life-Sustaining Treatment Program in the Clinical Setting: A Systematic Review of the Literature. J Am Geriatr Soc 2018. 2015;63(2):341-350.

33. Ng CWL, Cheong S, Govinda Raj A, Teo W, Leong I. End-of-life care preferences of nursing home residents: Results of a cross-sectional study. Palliative Medicine. 2016;30(9):843-853.

34. Givens JL, Sudore RL, Marshall GA, Dufour AB, Kopits I, Mitchell SL. Advance Care Planning in Community-Dwelling Patients With Dementia. J Pain Symptom Manage. 2018;55(4):1105-1112.

35. Molloy DW, Guyatt GH, Russo R, et al. Systematic Implementation of an Advance Directive Program in Nursing Homes: A Randomized Controlled Trial. JAMA 2000;283(11):1437-1444.

36. Morrison RS, Chichin E, Carter J, Burack O, Lantz M, Meier DE. The Effect of a Social Work Intervention to Enhance Advance Care Planning Documentation in the Nursing Home. J Am Geriatr Soc 2005;53(2):290-294.

37. Unroe KT, Fowler NR, Carnahan JL, et al. Improving Nursing Facility Care Through an Innovative Payment Demonstration Project: Optimizing Patient Transfers, Impacting Medical Quality, and Improving Symptoms: Transforming Institutional Care Phase 2. J Am Geriatr Soc. 2018;66(8):1625-1631.

38. Kahwati LC, Lewis MA, Williams PA, Kane H. Using qualitative comparative analysis to understand and quantify translation and implementation. TBM 2014;4:201-208. 
39. Sinuff T, Dodek P, You JJ, et al. Improving end-of-life communciation and decision making: The development of a conceptual framework and quality indicators. J Pain Symptom Manage. 2015;49:1070-1080.

40. Unroe KT, Hickman SE, Torke AM, Group ARCW. Care Consistency with Documented Care Preferences: Methodologic Considerations for Implementing the "Measuring What Matters" Quality Indicator. J Pain Symptom Manage 2016;52(4):453-458.

41. Detering KM, Hancock AD, Reade MC, Silvester W. The Impact of Advance Care Planning on End of Life Care in Elderly Patients: Randomised Controlled Trial. BMJ 2010;340:c1345.

\section{Figure Legend}

Figure 1. Bivariate and multivariable models of the association between advance care planning documentation status, all-cause hospitalizations, and potentially avoidable hospitalizations. 
Table 1. Participant characteristics and covariates by advance care planning documentation outcomes.

\begin{tabular}{|c|c|c|c|c|c|}
\hline \multirow[t]{2}{*}{ Variables } & & \multicolumn{4}{|c|}{ Group comparison } \\
\hline & $\begin{array}{c}\text { Total } \\
\text { sample } \\
(\mathrm{N}=1482)\end{array}$ & $\begin{array}{c}\text { Comfort } \\
\text { Measures/Do } \\
\text { Not } \\
\text { Hospitalize } \\
(\mathrm{N}=493) \\
\end{array}$ & $\begin{array}{l}\text { ACP with no } \\
\text { hospitalization } \\
\text { limits } \\
(\mathrm{N}=771)\end{array}$ & $\begin{array}{c}\text { No ACP } \\
\text { documentation } \\
(\mathrm{N}=218)\end{array}$ & $p$-value \\
\hline Female, n (\%) & $\begin{array}{c}1000 \\
(67.5) \\
\end{array}$ & $370(75.1)$ & $486(63.0)$ & $144(66.1)$ & $<.001$ \\
\hline Age, mean (sd) & $\begin{array}{c}79.2 \\
(12.7)\end{array}$ & $84.6(9.2)$ & $77.0(13.1)$ & $74.5(14.1)$ & $<.001$ \\
\hline Age $>65, \mathrm{n}(\%)$ & $\begin{array}{c}1261 \\
(85.1)\end{array}$ & $478(97.0)$ & $619(80.3)$ & $164(75.2)$ & $<.001$ \\
\hline White race, $\mathrm{n}(\%)$ & $\begin{array}{c}1075 \\
(72.5)\end{array}$ & $404(82.0)$ & $520(67.4)$ & $151(69.3)$ & $<.001$ \\
\hline $\begin{array}{l}\text { Hospice or end stage } \\
\text { renal, } n(\%)\end{array}$ & $83(5.6)$ & $53(10.8)$ & $15(2.0)$ & $15(6.9)$ & $<.001$ \\
\hline $\begin{array}{l}\text { Cognitive Function } \\
\text { Scale, (REF) n (\%) }\end{array}$ & & & & & \\
\hline $\mathrm{N}$ & 1449 & 478 & 760 & 211 & $<.001$ \\
\hline cognitively intact & $\begin{array}{c}455 \\
(31.4)\end{array}$ & $73(15.3)$ & $282(37.1)$ & $100(47.4)$ & \\
\hline mildly impaired & $\begin{array}{c}338 \\
(23.3)\end{array}$ & $98(20.5)$ & $188(24.7)$ & $52(24.6)$ & \\
\hline $\begin{array}{l}\text { moderately } \\
\text { impaired }\end{array}$ & $\begin{array}{c}552 \\
(38.1)\end{array}$ & $259(54.2)$ & $249(32.8)$ & $44(20.9)$ & \\
\hline severely impaired & $104(7.2)$ & $48(10.0)$ & $41(5.4)$ & $15(7.1)$ & \\
\hline Depression, n (\%) & $\begin{array}{c}843 \\
(56.9)\end{array}$ & $283(57.4)$ & 439 (56.9) & $121(55.8)$ & .920 \\
\hline Feeding tube, n (\%) & $91(6.1)$ & $25(5.1)$ & $51(6.6)$ & $15(6.9)$ & .476 \\
\hline Dialysis, n (\%) & $42(2.9)$ & $3(0.6)$ & $24(3.2)$ & $15(6.9)$ & $<.001$ \\
\hline Anemia, n (\%) & $\begin{array}{c}607 \\
(41.0) \\
\end{array}$ & $187(37.9)$ & $323(41.9)$ & $97(44.5)$ & .195 \\
\hline Pneumonia, n (\%) & $36(2.4)$ & $13(2.6)$ & $17(2.2)$ & $6(2.8)$ & .840 \\
\hline $\mathrm{CHF}, \mathrm{n}(\%)$ & $\begin{array}{c}415 \\
(28.0)\end{array}$ & $136(27.6)$ & $205(26.6)$ & $74(33.9)$ & .099 \\
\hline Cancer, n (\%) & $90(6.1)$ & $31(6.3)$ & $40(5.2)$ & $19(8.7)$ & .154 \\
\hline COPD, n (\%) & $\begin{array}{c}402 \\
(27.1)\end{array}$ & $108(21.9)$ & $227(29.4)$ & $67(30.7)$ & .006 \\
\hline $\begin{array}{l}\text { Activities of Daily } \\
\text { Living score, mean } \\
\text { (SD) }\end{array}$ & $19.0(4.5)$ & $20.2(3.6)$ & $18.3(4.9)$ & $18.7(4.4)$ & $<.001$ \\
\hline
\end{tabular}

Note: Chi-square used for categorical variables; Kruskal-Wallis non-parametric test used for continuous variables. 
Table 2. OPTIMISTIC Project advance care planning documentation for residents enrolled from January 1, 2015 to June 30, 2016.

\begin{tabular}{|c|c|c|}
\hline & $\begin{array}{c}\text { Comfort } \\
\text { Measures/Do Not } \\
\text { Hospitalize } \\
(\mathrm{N}=493)\end{array}$ & $\begin{array}{l}\text { ACP with no } \\
\text { hospitalization } \\
\text { limits } \\
(\mathrm{N}=771)\end{array}$ \\
\hline POST Form, N (\%) & $480(97.4)$ & $355(46.0)$ \\
\hline \multicolumn{3}{|l|}{ Section A - Resuscitation } \\
\hline Full Code, n (\%) & $0(0.0)$ & $137(38.6)$ \\
\hline Do Not Resuscitate, n (\%) & $480(99.4)$ & $218(61.4)$ \\
\hline \multicolumn{3}{|l|}{ Section B - Medical Interventions } \\
\hline Comfort measures, $\mathrm{n}(\%)$ & $480(100.0)$ & $0(0.0)$ \\
\hline Limited Additional Interventions, n (\%) & $0(0.0)$ & $205(57.8)$ \\
\hline Full Treatment, $\mathrm{n}(\%)$ & $0(0.0)$ & $148(41.7)$ \\
\hline Not Chosen, $\mathrm{n}(\%)$ & $0(0.0)$ & $2(0.5)$ \\
\hline \multicolumn{3}{|l|}{ Section C - Antibiotics } \\
\hline Antibiotics for comfort measures only, $\mathrm{n}(\%)$ & $191(39.8)$ & $30(8.4)$ \\
\hline Antibiotics consistent with treatment goals, $\mathrm{n}(\%)$ & $286(59.6)$ & $318(89.6)$ \\
\hline Not Chosen, $\mathrm{n}(\%)$ & $3(0.6)$ & $7(2.0)$ \\
\hline \multicolumn{3}{|l|}{ Section D - Artificial Nutrition } \\
\hline No Feeding tube, n (\%) & $441(91.9)$ & $165(46.5)$ \\
\hline Time Limited Trial, $\mathrm{n}(\%)$ & $12(2.5)$ & $60(16.9)$ \\
\hline Full Intervention, n (\%) & $8(1.7)$ & $90(25.3)$ \\
\hline Not Chosen, $\mathrm{n}(\%)$ & $19(3.9)$ & $40(11.3)$ \\
\hline No POST Form, N (\%) & $13(2.6)$ & $416(54.0)$ \\
\hline Full Code, n (\%) & $0(0.0)$ & $201(48.3)$ \\
\hline Do Not Resuscitate, n (\%) & $13(100.0)$ & $207(49.8)$ \\
\hline Do Not Hospitalize, $\mathrm{n}(\%)$ & $13(100.0)$ & $0(0.0)$ \\
\hline
\end{tabular}

Note: Table excludes $n=218$ residents with no advance care planning documentation on file. 
Table 3. Unadjusted rates of hospitalizations per 1000 resident days by advance care planning status.

\begin{tabular}{|l|c|c|}
\hline & $\begin{array}{c}\text { All-cause } \\
\text { hospitalizations } \\
\text { (per 1000 resident days) }\end{array}$ & $\begin{array}{c}\text { Potentially avoidable } \\
\text { hospitalizations } \\
\text { (per 1000 resident days) }\end{array}$ \\
\hline $\begin{array}{l}\text { Comfort measures/Do not } \\
\text { hospitalize orders }\end{array}$ & 1.5 & 0.4 \\
\hline $\begin{array}{l}\text { ACP orders with no } \\
\text { hospitalization limits }\end{array}$ & 2.0 & 0.5 \\
\hline $\begin{array}{l}\text { No ACP or hospitalization } \\
\text { limits }\end{array}$ & 2.7 & 0.9 \\
\hline
\end{tabular}

Note: ACP = advance care planning. 


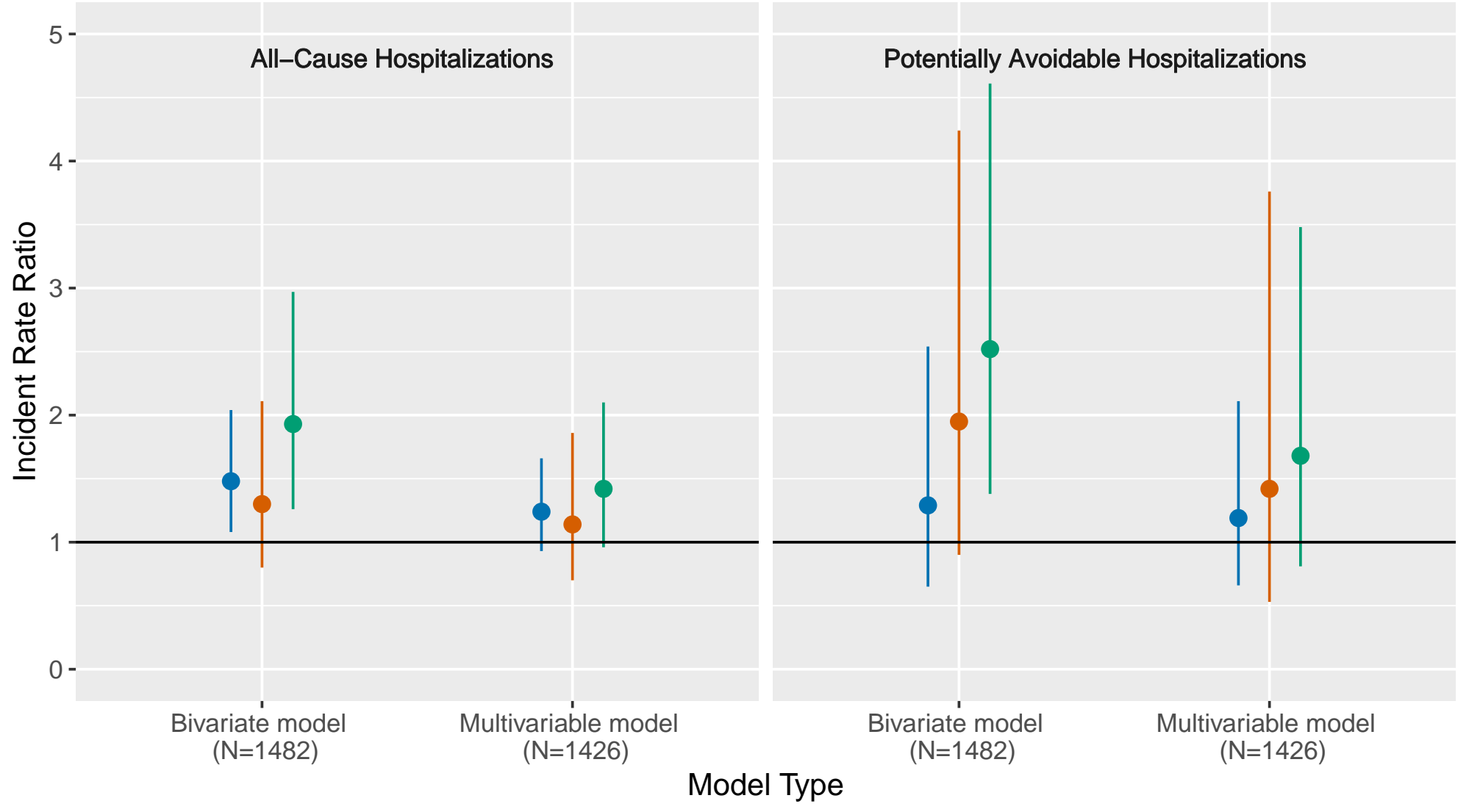
Comparison: No ACP vs. ACP with no hospitalization limits
No ACP vs. Comfort Measures/Do Not Hospitalize

Note: $\mathrm{ACP}=$ advance care planning 